\title{
ARTIGOS
}

\section{Formação acadêmico-profissional de professores(as)}

\author{
Elena Maria Billig \\ Diana Paula Salomão de Freitas
}

Assumimos a formação de professores(as) como acadêmico-profissional, pois temos como premissa que a profissão professor tem suma relevância no processo de transformação humana e, sendo assim, faz-se necessário que universidade e escola de educação básica compartilhem esta responsabilidade formativa (DINIZ-PEREIRA, 2008). Neste entendimento, diferente de compreender a formação de professores(as) em processos denominados de "formação inicial" e de "formação continuada", posicionamo-nos pelo que o professor Diniz-Pereira designou "formação acadêmico-profissional". Buscamos promover práticas educativas realizadas entre professores(as) experientes e iniciantes, em parceria universidade e escola, para atingirmos objetivos comuns, na (re)construção do conhecimento e em proposições transformadoras da realidade.

Diniz-Pereira (2008) defende a necessidade de a formação dos professores(as) ser assumida como acadêmico-profissional, ao problematizar o termo 'formação inicial' " [...] tão vastamente difundido na literatura da área da educação e adotado acriticamente por meio da importação de resultados de pesquisas realizadas em contextos educacionais bastante diferentes daqueles encontrados em nosso País" (DINIZ-PEREIRA, 2008, p. 253).

Mello (2010) inter-relaciona a formação dos(as) professores(as) e a valorização docente. A discussão sobre a valorização docente nas discussões políticas se tornou mais evidente no cenário neoliberal, a partir de 1990, com a "culpabilização" dos professores(as) pelos problemas educacionais (MELLO, 2010, p. 79). Essa assunção desconsiderava que faltava formação específica para os professores(as), além de valorização financeira e prestígio social (Ibidem). A valorização dos(as) professores(as) é proveniente de fontes que podem ser elencadas em fatores, dentre os quais reproduzo os citados por Mello:

[...] a formação intelectual e ética dos professores(as) para os desafios do seu trabalho; a constituição de uma identidade profissional, dada não só pelo saber científico como pela luta e organização sindical que redunde em auto-estima e reconhecimento social; a decisão política do Estado para tirar os entraves que impedem o pagamento de salários dignos, calculados pela jornada integral e dedicação exclusiva do professor na escola, balizados por um Piso Salarial Profissional Nacional (MELLO, 2010, p. 70).

Fatores esses que podem ser resumidos em necessidade de formação continuada, melhoria das condições de trabalho, de plano de carreira e de remuneração, imprescindíveis para se pensar sobre a responsabilidade do(a) professor(a) no processo de mediação da formação humana.

Diniz-Pereira aposta na formação compartilhada entre universidade e escola afirmando: "[...] discutir desafios e potencialidades para o estabelecimento de parcerias (entendidas aqui como iniciativas conjuntas para se atingirem objetivos comuns) entre universidades e escolas para a formação de profissionais da Educação Básica no Brasil" (DINIZ-PEREIRA, 2008, p. 265). Argumentou o professor sobre a inadequação e uso acrítico dos termos "formação pré-serviço" ou "formação inicial", para caracterizar a formação daqueles que atuarão na Educação Básica brasileira. Em relação ao termo “formação pré-serviço", o professor manifestou que esse 


\section{autêntica}

DOI https://doi.org/10.31639/rbpfp.v\%vi\%i.215

desconsidera o fato de que em várias regiões brasileiras ainda existem profissionais que exercem o magistério sem a habilitação mínima exigida (Ibidem). Ou seja, "existe ainda no País um grande contingente de pessoas que, ao ingressar em um curso ou programa de formação docente, em uma instituição de ensino superior, já atua no magistério há vários anos" (DINIZ-PEREIRA, 2008, p. 255) e, por isso, não se pode denominar, para esses, que a formação em nível superior, seja formação "pré-serviço" (sic).

Outro termo problematizado pelo professor é o que denominamos de "formação inicial", que tem sido cunhado de maneira inadequada na medida em que desconsidera que os processos de escolarização são iniciados antes de escolhida a carreira docente e, sendo assim, o termo "carrega consigo a ideia de uma preparação que se inicia a partir da entrada do futuro professor em um programa de formação docente, desconhecendo, dessa maneira, momentos e experiências anteriores importantíssimos nesse processo de formação" (DINIZ-PEREIRA, 2008, p.265).

Assim, Diniz-Pereira defende que em vez de "formação inicial" seja utilizado o termo "formação acadêmico-profissional" (Ibidem) nesta etapa da formação que acontece no interior das instituições de Ensino Superior, para a qual o professor também alega que seja realizado no interior das escolas de Educação Básica, de modo que seja compartilhada por ambas instituições a responsabilidade de preparar novos profissionais da educação (lbidem).

Assumir a profissionalização da docência é necessário, inclusive para o enfrentamento de posições que, do ponto de vista político-ideológico neoliberal, procuram minimizar o impacto da formação permanente sobre a prática docente e, com base em pesquisas produzidas em contextos educacionais bem diferentes do contexto educacional brasileiro, afirmam ser "quase nulo" o impacto da conhecida "formação inicial" na mudança da prática docente. Defendem a flexibilização e/ou a desregulamentação da chamada "formação inicial", arguindo absurdamente pela diminuição da carga horária dessa formação, recomendando que seja realizada em instituição de ensino superior, "menos caras que as universidades" (Ibidem).

Nesta mesma linha, Freire já defendia que "Ser professora implica assumir uma profissão [...] que envolve certa tarefa, certa militância, certa especificidade no seu cumprimento" (FREIRE, 1997, p. 9). E, com intenção de "mostrar que a tarefa do ensinante, que é também aprendiz, sendo prazerosa é igualmente exigente" (FREIRE, 1997, p. 8), Freire se posiciona indicando que esta tarefa nos insere em uma busca prazerosa e igualmente exigente. "Exigente de seriedade, de preparo científico, de preparo físico, emocional, afetivo" (Ibidem, p. 8) e esta "exigência basilar" se efetiva na formação permanente de professores(as). "Formação permanente autêntica - a que se funda na experiência de viver a tensão dialética entre teoria e prática" (lbidem, p. 11). Em Freire, encontramos uma ideia que sintetiza esta compreensão.

A prática educativa, pelo contrário, é algo muito sério. Lidamos com gente, com crianças, adolescentes ou adultos. Participamos de sua formação. Ajudamo-los ou os prejudicamos nesta busca. Estamos intrinsecamente a eles ligados no seu processo de conhecimento. Podemos concorrer com nossa incompetência, má preparação, irresponsabilidade, para o seu fracasso. Mas podemos, também, com nossa responsabilidade, preparo científico e gosto do ensino, com nossa seriedade e testemunho de luta contra as injustiças, contribuir para que os educandos vão se tornando presenças marcantes no mundo (FREIRE, 1997, p. 32. Grifos nossos).

Diniz-Pereira apresenta possibilidades para repensar a formação de professores(as) no mundo e em nosso país, colocadas pelo movimento reformista da formação acadêmico-profissional de professores(as) da Educação 


\section{autêntica}

DOI https://doi.org/10.31639/rbpfp.v\%vi\%i.215

Básica, que, no início da década de 1980, nos Estados Unidos e no Canadá, começava e se disseminar por vários países, incluindo os latino-americanos, na busca pela reflexão sobre a profissionalização do trabalho docente (DINIZ-PEREIRA, 2011). Dentre outros, o professor citou como princípios comuns desse movimento:

[...] conceber o ensino como uma atividade profissional apoiada em um sólido repertório de conhecimentos, entender a prática profissional como um lugar de formação e de produção de saberes pelos práticos e estabelecer ligação entre as instituições universitárias de formação e as escolas da Educação Básica" (DINIZ-PEREIRA, 2011, p. 213. Grifos nossos).

Nos processos de formação de professores(as) dos quais participamos, buscamos estabelecer relações de parceria - "iniciativas conjuntas para se atingirem objetivos comuns" (DINIZ-PEREIRA, 2008, p.265), pelo diálogo entre professores(as) da Universidade e da Educação Básica, com diferentes experiências profissionais, o que também inclui licenciandos e licenciados. A presença de professores(as) da Educação Básica no coletivo da sala de aula favorece que situações atuais da escola sejam trazidas para dentro da universidade, além de estimular a participação dos(as) acadêmicos(as) em atividades realizadas em suas escolas.

A oportunidade de aprender com o outro, que é o(a) professor(a), que são os(as) estudantes ou os(as) colegas - incluindo as experiências compartilhadas pelas professoras da rede de Educação Básica - faz com que a reciprocidade do ensinar-aprender seja melhor percebida. "A educação é um ato intransitivo, quer dizer, o educador não pode transformar a outrem que não esteja se transformando no próprio trabalho de ensinar. Por isso é que ele, ao ensinar, ele aprende" (PINTO, 1987, p. 13). Em relação ao sentido social da educação, Pinto afirmou que:

[...] não haverá verdadeira função do professor senão mediante a intensificação das influências sociais e a compreensão cada vez mais clara que o educador tenha de que sua atividade é eminentemente social, influi sobre os acontecimentos em curso no seu meio e só pode ser valiosa se ele admite ser conscientemente participante desses acontecimentos" (PINTO, 1987, p. 75. Grifos nossos).

Nesse sentido, a partilha das situações da sala de aula da escola de Educação Básica, da Educação Superior e das experiências dos(as) licenciandos(as), mostra a riqueza presente na diversidade do coletivo em criar iniciativas conjuntas para o enfrentamento dos desafios do cotidiano escolar. A formação de professores(as) assumida como acadêmico-profissional, ao considerar os saberes dos(as) professores(as) em exercício e licenciandos(as), potencializa o impacto da formação permanente na formação cidadã, no sentido da criação de um espaço de participação democrática e na prática docente. Isso permite que situações da escola de Educação Básica sejam trazidas para a universidade e estimula a participação dos(as) licenciandos(as) em atividades realizadas nas escolas.

Para Pimenta e Anastasiou (2002), a formação de professores(as) acontece em processo de profissionalização, efetivados por meio de ações reflexivas que possibilitam o entrelaçamento dos saberes da experiência, dos saberes do conhecimento e dos saberes pedagógicos, constituindo os saberes da docência. Saberes esses (re)construídos também a partir de referências das vivências com docentes, estudantes, especialistas, colegas, enfim com aqueles(as) que participam de processos de formação ao longo da escolarização e na prática profissional nas diversas instâncias.

A concepção da formação acadêmico-profissional de professores(as) perpassa também pelo entendimento de docência como "ação educativa e como processo pedagógico intencional e metódico, envolvendo 


\section{autêntica}

DOI https://doi.org/10.31639/rbpfp.v\%vi\%i.215

conhecimentos específicos, interdisciplinares e pedagógicos, conceitos, princípios e objetivos da formação que se desenvolvem na socialização e construção de conhecimentos, no diálogo constante entre diferentes visões de mundo" (DOURADO, 2015, p. 315), que acontece na interação entre sujeitos envolvidos no Ensino Superior e na Educação Básica.

Em suma, compreender a formação de professores como acadêmico-profissional permite constatar que a profissão docente é mediadora e produtora de saberes e, por isso, envolve tarefas exclusivas que exigem seriedade, responsabilidade, posicionamento político, preparo científico, criticidade, reflexividade, criatividade, preparo físico, emocional e afetivo, eticidade e outras características, que se desenvolvem na participação dos(as) professores(as) em processos de formação permanente, constituído por um coletivo integrado por profissionais com diferentes experiências.

A relevância de nos assumirmos parceiros(as), visto que a participação de um coletivo diversificado, ajuda na busca, na dinamização e nas proposições de práticas para problematizarmos as muitas informações pertinentes a um tema estudado, especialmente porque essas informações são cindidas por interesses objetivamente contraditórios e por grupos que lutam por estes interesses.

Dada a responsabilidade imbuída na formação dos profissionais que formarão outras pessoas e para contribuir com a formação de professores(as), enquanto aspecto da valorização docente, compreender a formação de professores(as) como acadêmico-profissional ajuda a entender a necessidade deste processo complexo ser compartilhado pelo campo de trabalho profissional (escola de Educação Básica) e o espaço de formação/ trabalho acadêmico (instituições de Educação Superior), com carga horária determinada e em grupos constituído por professores(as) experientes e iniciantes, para trabalhar e produzir conhecimentos específicos à formação humana. 


\section{autêntica}

DOI https://doi.org/10.31639/rbpfp.v\%vi\%i.215

\section{REFERÊNCIAS}

BRASIL. Ministério da Educação. Conselho Nacional de Educação. Conselho Pleno. Resolução CNE/ $\mathrm{CP} \mathrm{n}^{\circ} 2$, de $1^{\circ}$ de Julho de 2015. Define as Diretrizes Curriculares Nacionais para a formação inicial em nível superior (cursos de licenciatura, cursos de formação pedagógica para graduados e cursos de segunda licenciatura) e para a formação continuada. Disponível em http://portal.mec.gov.br/index. php?option=com_docman\&view=download\&alias=17719-res-cne-cp-002-03072015\&category_slug=julho2015-pdf\&Itemid=30192 Acesso em 12/03/2017.

Ministério da Educação. Conselho Nacional de Educação. Parecer CNE/CP n: 2, de 09 de junho de 2015. Diretrizes Curriculares Nacionais para a Formação Inicial e Continuada dos Profissionais do Magistério da Educação Básica. Disponível em http://portal.mec.gov.br/index.php?option=com_docman\&view=download\&alias=17625-parecer-cne-cp-2-2015-aprovado-9-junho-2015\&category_slug=junho-2015-pdf\&ltemid=30192 Acesso em 12/03/2017.

Presidência da República. Casa Civil. Subchefia para Assuntos Jurídicos. Decreto nº 8.752, de 09 de maio de 2016. Dispõe sobre a Política Nacional de Formação dos Profissionais da Educação Básica. Brasília, 2016. Disponível em http://www.planalto.gov.br/ccivil_03/_Ato2015-2018/2016/Decreto/D8752.htm\#art19 Acesso 12/03/2017.

DINIZ-PEREIRA, Júlio Emílio. A formação acadêmico-profissional: compartilhando responsabilidades entre as universidades e escolas. TRAVERSINI, Clarice et al.(Orgs.). Trajetórias e processos de ensinar e aprender: didática e formação de professores. 1. ed. Porto Alegre: EDIPUCRS, 2008, v. 1, p. 253-267.

A prática como componente curricular na formação de professores. Educação, Santa Maria, v. 36, n. 2, p. 203-218, maio/ago. 2011.

DOURADO, Luiz Fernando. Diretrizes Curriculares Nacionais para a Formação Inicial e Continuada dos Profissionais do Magistério da Educação Básica: concepções e desafios. Educ. Soc., Campinas, v. 36, n. 131, p. 299-324, abr.-jun., 2015.

FREIRE, Paulo. Professora sim tia não: cartas a quem ousa ensinar. São Paulo: Editora Olho d’Água, 1997.

MELLO, Elena Maria Billig. As Políticas de Valorização e Profissionalização dos Professores da Educação Básica do Estado do Rio Grande do Sul (1995-2006): convergências e divergências. Porto Alegre: POA, 2010, 241 f. Tese (Doutorado) - Programa de Pós-graduação em Educação, Universidade Federal do Rio Grande do Sul, Porto Alegre, 2010.

PIMENTA, Selma G.; ANASTASIOU, Léa (Orgs.). Docência no Ensino Superior. São Paulo: Cortez, 2002.

PINTO, Alvaro Vieira. Sete Lições sobre Educação de Adultos. São Paulo: Autores Associados: Cortez, 1987. 
